\begin{tabular}{|c|c|}
\hline Postprint Version & 1.0 \\
\hline Journal website & http://www3.interscience.wiley.com/journal/122648603/abstract \\
\hline Pubmed link & http://www.ncbi.nlm.nih.gov/pubmed/19824065 \\
\hline DOI & $10.1002 /$ jts.20461 \\
\hline
\end{tabular}

This is a NIVEL certified Post Print, more info at http://www.nivel.eu

\title{
'Impact of a Technological Disaster on Young Children: A Five-Year Postdisaster Multiinformant Study
}

\author{
Frits Boer Academic Medical Centre Department of ChILd and Adolescent Psychiatry/ DE \\ BASCULE, AMSTERDAM, THE NeTHERLANDS
}

Cees Smit Twente Public Health Service (GgD Regio Twente), Enschede, the Netherlands

MATtiJn MorRen THE NETHERLANDS INSTITUTE FOR HEALTH SERVICES RESEARCH (NIVEL), UTRECHT, THE NETHERLANDS

Jan Roorda Twente Public Health Service (GgD Regio Twente), Enschede, the NETHERLANDS

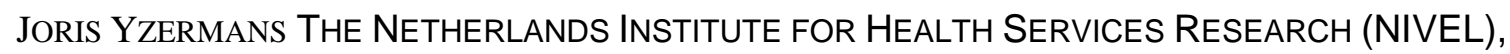
UTRECHT, THE NETHERLANDS

The Netherlands Institute for Health Services Research (NIVEL), Utrecht, the Netherlands Children exposed to a technological disaster during an understudied part of the lifespan, preschool age and early middle childhood, were assessed in a 5-year follow-up regarding mental health problems, anxiety disorder symptoms, depressive symptoms, physical symptoms, and posttraumatic stress symptoms. Exposed children and their parents $(n=264)$ reported significantly more problems than controls $(n=515)$. The differences were greater for conduct problems (including hyperactivity) and physical symptoms, than for anxiety and depression.

The long-term effects of a technological disaster on children of pre-school age at exposure appear to differ from those in children, who were victimized at a later age. This may reflect interference with completion of specific developmental tasks.

Exposure to a disaster is a shocking experience for adults as well as children, which may temporarily impede normal functioning.

Most people eventually succeed in overcoming the shock and regain their former level of functioning, or even show posttraumatic growth (Christopher, 2004). However, a substantial minority develops health problems, sometimes of a long lasting nature.

Posttraumatic stress disorder (PTSD) is prototypical, but many other disorders may be caused or augmented by stressful experiences, e.g., other anxiety disorders, depression, conduct disorders, substance abuse, and diverse physical symptoms. The impact of disaster will differ according to the developmental stage of the victim. Therefore, disaster research should be aimed at victims from different developmental stages. When children are studied a special difficulty occurs in objectifying postdisaster functioning.

The younger a child, the more it is necessary to use other informants than the child itself, especially the parents. When children get older, it becomes possible to include self-report. Most commonly used research instruments, e.g., self-report questionnaires, are applicable for children of about nine years and onwards (Angold, 2002). This has led to a plethora of studies in which the impact of a disaster is studied in 
Boer, F., Smit, C., Morren, M., Roorda, J., Yzermans, J. Impact of a technological disaster on young children: a five-year postdisaster multiinformant study. Journal of Traumatic Stress: 2009, 22(6), 516-524

children in middle childhood (usually third grade and above) or adolescence at the time of exposure (e.g., the 1988 Armenian earthquake, Goenjian et al., 1995; the 1988 Jupiter cruise ship sinking, Bolton, O’ Ryan, Udwin, Boyle, \& Yule, 2000; the 1989 Hurricane Hugo, Lonigan, Shannon, Taylor, Finch, \& Sallee,1989; the 1992 Hurricane Andrew, La Greca, Silverman, Vernberg, \& Prinstein, 1996; the 1994Northridge earthquake, Asarnow et al, 1999; the 1995Oklahoma City bombing, Pfefferbaum et al., 1999; the 2001 September 11 World Trade Center (WTC) terrorist attack, Hoven et al., 2005; the 2004 Tsunami, Neuner, Schauer, Catani, Ruf,\&Elbert, 2006; the 2005 Hurricane Katrina, Weems et al., 2007). There are far fewer studies of children of preschool age at the time of exposure (e.g., the 1972 Buffalo Creek Dam collapse, Green et al., 1991; the 1988 Montreal PCB Warehouse fire, Breton, Valla, \& Lambert, 1993; the 1994 Northridge earthquake, Proctor, Fauchier, Oliver, Ramos, \& Margolin, 2007; the 1996 Aubou'e Mine collapse, Vila et al., 2001; the 2001 September 11 WTC terrorist attack, Chemtob, Nomura, \& Abramovitz, 2008) that typically rely on parent report. This state of affairs has created a gap in our knowledge of the impact of disaster on young children (preschool through elementary school grades 1 and 2). It has been suggested that preschool age children show a higher incidence of specific behavioral disturbances, including trauma-specific and generalized fears, regressive habits, distractibility and aggressiveness, whereas school-age children respond with trauma-specific fears and anxieties, somatic concerns, sleep disturbance, and school problems. Adolescents show themore traditional PTSDsymptoms (Green et al., 1991). In all the studies of children in middle childhood or adolescence at the time of the disaster cited above the short-term (between 3 months and 2 years after exposure) effects are mainly of an internalizing nature (PTSD, anxiety, depression).

In the studies of children in preschool age during exposure two of four (Chemtob et al., 2008; Green et al., 1991) externalizing symptoms (belligerence, aggression) are reported in addition to the omnipresent internalizing symptoms. One study (Chemtob et al., 2008) reports sleeping problems as well. In a 2-year postdisaster study of children exposed to the fireworks disaster in Enschede, theNetherlands (Dirkzwager, Kerssens,\&Yzermans, 2006) health problems as recorded by family practitioners show an increase in sleep problems in children aged 4 to 12 years old compared with controls, and an increase in anxiety problems in children and young adults aged 13 to 18 years old in comparison with controls.

There is a paucity of data on the long-term effects of disaster experienced during childhood. Long-term (5-8 years) follow-ups are available about the originally school age and adolescent populations exposed to the Armenian earthquake (Goenjian et al., 2005) and the Jupiter cruise ship sinking (Bolton et al., 2000), that show a persistence of internalizing symptoms (PTSD, depression) in a declining, but still substantial group. The only long-term followup (17 years) of a population that included preschool-age children at exposure has been performed with the victims of the Buffalo Creek Dam collapse (Green et al., 1994). After 17 years, there is still a small but significant difference between victims and controls from the region in the occurrence of PTSD. Symptoms do not differ anymore for the three age groups (preschool age, school age, or adolescence at the time of the disaster).

The literature on the impact of disaster on children of different age groups poses questions as well about the differential value of child-report and parent-report, as findings about the discrepancies between parent and child report of post-disaster functioning are equivocal. Some studies show that parents tend to underestimate posttraumatic symptomatology in their children, and therefore advocate to rely on child report (Meiser-Stedman, Smith, Glucksman, Yule, \& Dalgleish, 2007; Shemesh et al., 2005). In contrast, other studies show that parents tend to overreport posttraumatic symptoms of their children (Bromet et al., 2000). Interestingly, these contrasting findings are ascribed to the same factor: a bias due to parental posttraumatic symptoms.

The present study expands on earlier studies by assessing physical and psychological functioning of children aged 4 to 9 at the time of the Enschede (the Netherlands) fireworks disaster 5 years afterwards.

Posttraumatic stress disorder symptoms, and symptoms of other anxiety disorders, depressive symptoms, other psychological problems, and physical symptoms are assessed using standardized instruments presented to both parents and children of exposed families, as well as to nonexposed controls from the same region. 
Boer, F., Smit, C., Morren, M., Roorda, J., Yzermans, J. Impact of a technological disaster on young children: a five-year postdisaster multiinformant study. Journal of Traumatic Stress: 2009, 22(6), 516-524

\section{METHOD}

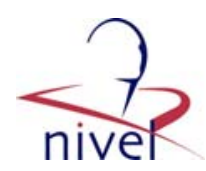

\section{Background}

On May 13, 2000, the explosion of a fireworks depot largely destroyed the surrounding neighborhood in the city of Enschede, the Netherlands. Twenty-two people were killed, almost 1,000 were injured, and about 400 families lost their homes. Many children were exposed to the disaster directly or indirectly. The Dutch government declared the explosion a national disaster, and initiated the Enschede Firework Disaster Health Monitoring Project to examine the health impact of the explosion on exposed residents and rescue workers to organize and provide appropriate aftercare (Roorda, Van Stiphout, \& Huijsman-Rubingh, 2004).

\section{Participants}

The regional health authority in Enschede employs health professionals who routinely examine the medical and psychosocial condition of schoolchildren. This examination was completed for 4,539 children who attended the second, fourth, and seventh grades during the school years 2001-2002, 2002-2003, and 2003- 2004 (cf. Smilde-Van den Doel, Smit, \& Wolleswinkel-Van den Bosch, 2006). As part of the examination, parents were asked to indicate whether or not their child was a victim of the disaster.

This information was used to select victim and control children for the present study, roughly 5 years after the disaster. Children in schools with less than five victims were excluded for practical reasons, leaving 3,611 children eligible. Subsequently, all 815 victims and a selection of 1,680 control children were sampled; about twice as many control children were selected because a lower participation rate was anticipated. After excluding 136 children for various reasons (e.g., school unable to participate, migrated), 2,359 children from 38 primary and secondary schools were invited to participate.

\section{Measures}

Mental health problems were assessed using the Strengths and Difficulties Questionnaire (Goodman, 1997; Van Widenfelt, Goedhart, Treffers, \& Goodman, 2003). The Strengths and Difficulties Questionnaire has 25 items, answered on a 3 -point scale $(0=$ not true, $1=$ somewhat true, $2=$ certainly true $)$, in five subscales: emotional symptoms, conduct problems, hyperactivityinattention, peer relationship problems, and prosocial behavior (five items each). A total difficulties score can be calculated by summing the scores on the first four subscales (range $=0-40$ ).

Higher scores reflect more difficulties. Both self-report (Goodman, Meltzer, \& Bailey, 1998) and parentreport version were administered (Goodman, 1997), for which good validity and reliability are reported (Van Widenfelt et al., 2003).

Anxiety disorders symptoms were examined, both through self-report and parent-report, with the Screen for Child Anxiety Related Emotional Disorders (Birmaher et al., 1997; Muris, Merckelbach, Schmidt, \& Mayer, 1999). The scale's 38 items are answered on a 3-point scale $(0=$ almost never, $1=$ sometimes, and 2 $=$ often; range $=0-76)$. Five anxiety dimensions are assessed: panic disorder symptoms (13 items), generalized anxiety disorder symptoms (9 items), separation anxiety disorder symptoms (8 items), social phobia (4 items), and school anxiety (4 items). The 5-factor structure of the Screen for Child Anxiety Related Emotional Disorders has been replicated with both children (Muris et al., 1999) and adolescents (Hale, Raaijmakers, Muris, \& Meeus, 2005). Good internal consistency and construct validity are reported (e.g. Hale et al., 2005; Muris, Dreessen, B"ogels, Weckx, \& van Melick, 2004; Muris, Merckelbach, Ollendick, King, \& Bogie, 2002).

Depression was assessed through self-report and parent-report with the nine-item Short Depression Inventory for Children (De Wit, 1987), which has a true-false response format (range $=0-9$ ).

Psychometric characteristics of the scale are excellent (De Wit \& Kroesbergen, 1992; Meier, Mellenbergh, \& De Wit, 1986).

Physical symptoms were catalogued, again through self-report and parent-report, using the Children's Somatisation Inventory (Meesters,Muris, Ghys, Reumerman,\&Rooijmans, 2003;Walker \& Garber, 1992), which assesses frequency of occurrence of 35 physical symptoms in the 2 previous weeks. Children answer on a 5 -point scale $(0=$ not at all, $1=$ a little, $2=$ somewhat, $3=a$

lot, and $4=$ a whole lot; range $=0-140$ ). Higher scores reflect a higher intensity of somatic complaints. Posttraumatic stress wasmeasuredwith the Children's Impact of Events Scale (CRIES-13; Smith, Perrin, Dyregrov, \& Yule, 2003; Olff, 2005), a child-adapted version of the Impact of Events Scale (Horowitz, Wilner, \& Alvarez, 1979) developed under auspices of the Children and War Foundation to catalogue the effects of war and disasters on children (Children and War Foundation, 1998). The CRIES-13 has 13 items 
in three subscales measuring symptoms of intrusive (4 items), avoidance (4 items), and arousal evoking (5 items) thoughts, images, and feelings. Responses indicate how frequently the child experiences these symptoms, and each question is answered on a 4-point scale $(0=$ not at all, $1=$ rarely, $3=$ sometimes, and 5 = often; range $=0-65)$. Parents filled out a parent-adapted version of the CRIES-13 (Olff, 2005).

The psychometric properties of theDutch version of theCRIES have not been established yet. In this study, alphas were .82 (intrusion, parents), .77 (intrusion, children), .79 (avoidance, parents), .74 (avoidance, children), .73 (arousal, parents), and .70 (arousal, children).

\section{Data Analysis}

Differences between exposed children and controls were tested for statistical significance using chi-squareand $t$-tests. Health differences between exposed and control children were tested through a series of logistic regression models. The following variables were used as covariates: child gender, ethnicity (non-Western vs.

Western), socioeconomic status (SES: public health insurance, indicative for lower and middle SES vs. private health insurance), household marital status (single parent vs. nonsingle parent), low education level of mother, and life events other than the fireworks disaster (having experienced at least one traumatic experience vs.

not having experienced traumatic experiences). These variables and exposure $(1=$ exposed; $0=$ control $)$ were entered into the regression simultaneously.

Because children and parents reported about the same participant, the child, their reports were not mutually independent.

Therefore, differences within parent-child pairs were analyzed with hierarchical models. All demographic variables mentioned above were entered into the regression; additionally odds ratios were adjusted for source ( 1 = child-report; 0 = parent-report). Exposed children were expected to report less favorable health than controls and children to report less favorable health than parents.

To examine to what extent parent and child report coincide in those exposed versus those not exposed, the interaction term Exposure $\times$ Source was included in the model.

The SPSS program for Windows was used for all analyses, except those involving hierarchical models, in which case Multilevel Models for Windows (MlWin) was used. For all statistical tests, the two-tailed significance level was set at .05.

\section{RE S U L T S}

\section{Sample Characteristics}

Nine hundred twenty-eight child questionnaires and 834 parent questionnaires were returned, resulting in 264 exposed and 515 control child-parent pairs, a response rate of $34.6 \%$ and $32.3 \%$, respectively. The response rate did not differ between victims and controls, $\chi^{2}(1, N=779)=1.20, n s$. The gender distribution of participating children did not differ from that of nonresponders, although participantswere slightly, but significantly younger ( $M=11.6$ years, $S D=1.1)$ than nonresponders $(M=12.0$ years, $S D=1.2)$ due to higher nonresponse on the secondary schools, $t(2357)=6.37, p<.001$.

During the 2001-2004 school health examinations, parents had filled out the Strengths and Difficulties Questionnaire about their children as well. This allowed the investigation of differences in scores regarding responding and nonresponding children. On all five subscales (conduct problems, emotional problems, hyperactivity/ inattention, peer problems, and prosocial behavior) scores regarding responding and nonresponding exposed children did not differ. There was, however, a difference regarding nonexposed children.

Nonresponding nonexposed families reported more conduct problems (15.5\% beyond the borderline cutoff point) in 2001- 2004 than responding families ( $8.2 \%$ beyond the borderline cutoff point), whereas no differences were found on all other four subscales.

The age and gender distributions of exposed and control childrenwere similar, with amean age of 11.7 years (range $=9.3-14.5$ ) and $52.1 \%$ being female. There were no significant differences between parents of exposed and control children with regard to age, marital status, number of adults in the family, number of children in the family, educational level, public insurance, or ethnicity. Both groups differed, however, with respect to life events experienced after exposure to the disaster: Exposed children were reported to have 
Boer, F., Smit, C., Morren, M., Roorda, J., Yzermans, J. Impact of a technological disaster on young children: a five-year postdisaster multiinformant study. Journal of Traumatic Stress: 2009, 22(6), 516-524

1.58 life events on average $(S D=1.31)$, whereas control children were reported to have 1.29 life events on average $(S D=1.19)$, a significant difference, $t(777)=3.16, p<.01$.

\section{Prevalence of Health Problems Five Years After the Disaster}

Table 1 shows the prevalence of health problems and the adjusted odds ratio for exposed children versus controls as reported by children and their parents.

The percentages of exposed children showing psychological problems, anxiety, depression, posttraumatic stress reactions, and physical symptoms were higher than those of controls. This is the case for both childand parent-report. The significance of these differences was examined through logistic regression analyses, showing that exposed children and their parents reported significantly more conduct problems, hyperactivity/inattention, and physical problems than controls. Although exposed children and their parents both reported more health problems than controls, the differences between exposed and controls as reported by the parents more often reached significance. It is noteworthy that these differences were greater for conduct problems (including hyperactivity) and physical problems, than for anxiety and depression.

To investigate whether attrition had contributed to the difference in conduct problems, keeping in mind that nonexposed children with more serious conduct problems at the school health examinations in 20012004 were underrepresented in the group of children responding to the present study (see sample characteristics), we compared the 2001-2004 Strengths and Difficulties Questionnaire conduct problem scores regarding nonresponding nonexposed children,with those regarding nonresponding exposed children. Of nonresponding nonexposed children $15.5 \%$ were in the borderline range, versus $17.6 \%$ nonresponding exposed children.

Within these groups, $7.1 \%$ versus $9.7 \%$ were in the abnormal range, a significant difference, $\chi^{2}(1, N=779)$ $=6.37, p<.05$.

\section{Child-Report versus Parent-Report}

To examine whether children reported more health problems than their parents, a series of hierarchical regression analyses were conducted.

The results of these analyses show that in 8 of 13 health aspects, exposed children had more problems than controls, even after adjusting for source (child vs. parent).

Table 2 shows the results of the multilevel analysis with exposure, source, the interaction of exposure and source, and several potential confounders. The columns highlight exposure, source, and interaction term, respectively. If the interaction term is smaller than 1, the risk-enhancing aspects of being a child and being exposed stop reinforcing each other. In other words, in exposed households there is more agreement regarding psychological problems than in nonexposed households. For example, the odds ratio for an exposed child to reach the cutoff score on conduct problems is $2.06 \times 1.35=2.78$ times higher than the odds for other participants: the odds ratio (OR) is 2.78. This OR drops to 2.09 when the interaction term is included in themodel $(2.87 \times 0.75=2.09)$. These differences are significant for emotional problems and for the total score of the Strengths and Difficulties Questionnaire.

Figure 1 shows the differences for the Strengths and Difficulties Questionnaire variables between the models with and without the interaction term. Summing up, in families of exposed children there is less discrepancy between parent- and child-report of emotional problems and total difficulties than in families of control children.

\section{I S C U S S I O N}

This controlled study of children exposed to a technological disaster at a young age (4-9 years), followed up 5 years later, shows that victims have more psychological and health problems than nonexposed peers. Interestingly, the psychological problems are of an externalizing (conduct, hyperactivity) rather than internalizing (anxiety, depression) nature, and are accompanied by physical complaints. It shows that trauma-related problems are not confined to posttraumatic stress disorder and other anxietyrelated symptoms. This may even be more so when the traumatic event and the cascade of secondary stresses associated with it occur in early childhood and therefore interfere in a developmental period in which aggression regulation and the distinction between the emotional and physical expressions of distress are still to be acquired. 


\section{[TABLE 1] [TABLE 2]}

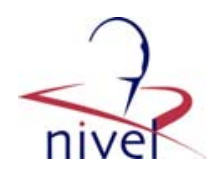

However, there are several reasons to interpret these results with caution. Somatic and psychological health was assessed through child parent-report. These are subjective measures, which tend to diverge. This poses questions of reliability. Therefore, we need to take a closer look at the issues of different informants and retrospective measurement.

The differences between parent- and child-report found in this study are to be expected, and do not necessarily render one source unreliable. Rather, the differences in report should be considered a reflection of differences in perspective, e.g., parents aremore aware of externally observable behavioral problems that children tend to play down, whereas children are considered better reporters of more internal problems, such as anxiety and depression. Furthermore, parents usually take a longer time span into consideration when reporting the problems of their child, in contrast to the inclination of children to report their current state. In this study, the results regarding control children are consistent with the large body of research showing that children tend to report more problems than parents. But in this study parents of exposed children and the children themselves show rather similar reports of the children's problems. The relatively higher level of children's problem behavior reported by parents of exposed children is sometimes considered the result of parental overreporting due to hypervigilance.

This is corroborated by the finding that parental worries about the effects of the Chernobyl disaster colored the parental assessment of the children's health.However, another possibility that should be considered is one of adequate reporting due to parental sensitivity for problems other parents tend to overlook. This interpretation contradicts a tendency in the literature to regard parents of traumatized children as less reliable reporters of their children's psychological problems. Although the design of this study does not allow definitive judgment about these competing hypotheses, this study warns against a hasty dismissal of parental report, especially about children who were still young at the time of the disaster.

The close contact between parents and young children may contribute to the parent's adequate appraisal of the problems the child developed in the wake of the disaster.

Parents of victims also reported more life events experienced by their child after the disaster than parents of controls. Again, this could reflect reporter bias, with parents of victims being more inclined to observe and report other life events. But it is equally possible that victims of the disaster are more prone to life events afterwards. Life events are sometimes a consequence of the disorder of the child (e.g., traffic accidents resulting from attentiondeficit/ hyperactivity disorder) and are then called dependent rather than independent life events (Sandberg, McGuinness, Hillary, \& Rutter, 1998); therefore, postdisaster symptomatology may contribute to a higher amount of life events. If so, we may be witnessing a selfreinforcing phenomenon, as life events in their own right contribute to postdisaster symptomatology. Consequently, it is of importance to explicitly distinguish dependent and independent life events in future research.

This study also shows limitations that need to be addressed.

The response rate was rather low. Although this is not uncommon for studies of children in the general population that depend on the consent of parents, it may have caused attrition bias. This concern is mitigated by the finding that response rates of victims and controls were similar. However, the information derived from parent-reported mental health problems during an earlier school health examination is somewhat equivocal. On the one hand, nonresponding families of nonexposed youngsters reported more conduct problems in 2001-2004 than responding families.

This difference was not found for families of exposed youngsters, and therefore attrition may have contributed to the difference in parent-reported conduct problems between exposed and nonexposed children in the present study. On the other hand, scores on the other problem scales, including hyperactivity, did not differ for exposed and nonexposed children and do not support the hypothesis of attrition bias due to severity of mental health problems.

And the validity of our finding of more conduct problems in exposed children was also supported by our finding of more conduct problems within the abnormal range that existed in 2001-2004 in exposed children that did not respond to the present study.

Exposure status was based on parent-report, and was not substantiated by formal criteria. This procedure may have led to inclusion of victims with varying degrees of exposure to the disaster. The results of this study show that all differences between exposed and controls point in the same direction, which provides 
support for the case-definition used. Another drawback was the fact that not all invited schools could manage to participate in the study. Relatively often, schools for secondary education did not consider participation feasible. Therefore, fewer young adolescents were included than initially intended. This implies that the results of this study have to be interpreted cautiously for this age group. This study was designed to assess self-reported or parent-reported health.The time available and restrictions set by cooperating schools prohibited an extensive clinical assessment, leading to a formal clinical diagnosis.

Thus, although this study shows that children report more health problems than their parents (even taking into consideration that cutoff scores for the Strengths and Difficulties Questionnaire are different for parents and children) it is not possible to decide which report is closer to the factual prevalence. Although clinically more relevant, the use of cutoff scores rather than the entire range of available scores tends to mitigate the results.

\section{[FIGURE 1]}

Parental health was not examined. There is evidence that the nature and intensity of the parental reaction to disaster predicts children's health problems after disaster (Gewirtz, Forgatch, \& Wieling, 2008; Proctor et al., 2007). The interaction with parental functioning is probably stronger in young children, who typically rely on attachment figures in their appraisal of stressful events. The assessment of parental health would also have been important, as it would have allowed the investigation of secondary traumatization of the children by parental psychopathology, a possible contributor to the behavioral problems of the children.

\section{Implications}

This study has two important messages. One has already been described extensively: Even 5 years after a technological disaster children that were in preschool age showmoremental and physical health problems than their nonexposed peers. The other message is more positive: The difference between exposed and nonexposed children is moderate, which implies that the majority of exposed children function well. How can we help exposed children to overcome their problems and join their nonexposed peers in their developmental trajectory? Recognition of their problems is the obvious first step. This study suggests that parents of these children should not be discarded as reporters of their children's difficulties. It is the parents who notice that even after 5 years some of the children exposed to a technological disaster still are symptomatic. And, most important, this study shows that the symptoms children exposed to disaster at a young age show in middle childhood and in adolescence differ from what is expected because of their externalizing and somatic nature. This highlights the need for developmentally sensitive research of the impact of disaster.

\section{REFEREN C ES}

Angold, A. (2002). Diagnostic interviews with parents and children. In M. Rutter \& E. Taylor (Eds.), Child and Adolescent Psychiatry (4th ed., pp. 32-52).

Oxford: Blackwell.

Asarnow, J., Glynn, S., Pynoos, R. S., Nahum, J., Guthrie, D., Cantwell, D. P., et al. (1999). When the earth stops shaking: Earthquake sequelae among children diagnosed for pre-earthquake psychopathology. Journal of the American Academy of Child and Adolescent Psychiatry, 38, 1016-1023.

Birmaher, B., Khetarpal, S., Brent, D., Cully, M., Kaufman, J., \& Neer, S. M. (1997). The Screen for Child Anxiety Related Emotional Disorders (SCARED): Scale construction and psychometric characteristics. Journal of the American Academy of Child and Adolescent Psychiatry, 36, 545-553.

Bolton, D., O' Ryan, D., Udwin, O., Boyle, S., \& Yule, W. E. (2000). The longterm psychological effects of a disaster experienced in adolescence: II: General psychopathology. Journal of Child Psychology and Psychiatry, 41, 513-523.

Breton, J. J., Valla, J. P.,\&Lambert, J. (1993). Industrial disaster and mental health of children and their parents. Journal of the American Academy of Child and Adolescent Psychiatry, 32, 438-445.

Bromet, E. J., Goldgaber, D., Carlson, G., Panina, N., Golovakha, E., Gluzman, S. F., et al. (2000).

Children's well-being 11 years after the Chornobyl catastrophe.

Archives of General Psychiatry, 57, 563-571.

Chemtob, C. M., Nomura, Y., \& Abramovitz, R. A. (2008). Impact of conjoined exposure to the World Trade Center attacks and to other traumatic events on the behavioral problems of preschool children. Archives of Pediatric and Adolescent Medicine, 162,126-133. 
Boer, F., Smit, C., Morren, M., Roorda, J., Yzermans, J. Impact of a technological disaster on young children: a five-year postdisaster multiinformant study. Journal of Traumatic Stress: 2009, 22(6), 516-524

Children andWar Foundation. (1998). The Children's Impact of Events Scale (13) (CRIES-13). Bergeh, Norway: Children and War Foundation.

Christopher, M. (2004). A broader view of trauma: A biopsychosocial-evolutionary view of the role of the traumatic stress response in the emergence of pathology and/or growth. Clinical Psychology Review, 24 75-98.

DeWit, C. (1987). Depressie Vragenlijst voor Kinderen DVK en KDVK [Depression Inventory for Children, DIC and SDIC, Manual]. Amersfoort, Netherlands: Acco.

De Wit, C. A. M., \& Kroesbergen, H. T. (1992). Depressieve symptomen bij kinderen: Vroege herkenning en zorg [Depressive symptoms in children: Early recognition and care]. Tijdschrift voor Gezondheidswetenschappen, 70, 477-483.

Dirkzwager, A. J. E., Kerssens, J. J., \& Yzermans, J. (2006). Health problems in children and adolescents before and after a man-made disaster. Journal of the American Academy of Child and Adolescent Psychiatry, 45, 94-103.

Gewirtz, A., Forgatch, M., \& Wieling, E. (2008). Parenting practices as potential mechanisms for child adjustment following mass trauma. Journal of Marital and Family Therapy, 34, 177-192.

Goenjian, A. K., Pynoos, R. S., Steinberg, A. M., Najarian, L. M., Asarnow, J. R., Karayan, I., et al. (1995). Psychiatric comorbidity in children after the 1988 earthquake in Armenia. Journal of the American Academy of Child and Adolescent Psychiatry, 34, 1174-1184.

Goenjian, A. K., Walling, D., Steinberg, A. M., Karayan, I., Najarian, L. M., \& Pynoos, R. (2005), A prospective study of posttraumatic stress and depressive reactions among treated and untreated adolescents 5 years after a catastrophic disaster. American Journal of Psychiatry, 162, 2302-2308.

Goodman, R. (1997). The Strengths and Difficulties Questionnaire: A research note. Journal of Child Psychology and Psychiatry, 38, 581-586.

Goodman, R., Meltzer, H., \& Bailey, V. (1998). The Strengths and Difficulties Questionnaire: A pilot study on the validity of the self-report version. European Child and Adolescent Psychiatry, 7, 125-130.

Green, B. L., Korol, M., Grace, M. C., Vary, M. G., Leonard, A. C., Gleser, G. C., et al. (1991). Children and disaster: Age, gender, and parental effects on PTSD symptoms. Journal of the American Academy of Child and Adolescent Psychiatry, 30, 945-951.

Green, B. L., Grace, M. C., Vary, M. G., Kramer, T. L., Gleser, G. C., \& Leonard, A. C. (1994). Children of disaster in the second decade: A 17-year follow-up of Buffalo Creek survivors. Journal of the American Academy of Child and Adolescent Psychiatry, 33, 71-79.

Hale III, W. W., Raaijmakers, Q. A. W., Muris, P., \& Meeus, W. H. J. (2005).

Psychometric properties of the screen for child anxiety related emotional disorders (SCARED) in the general adolescent population. Journal of the American Academy of Child and Adolescent Psychiatry, 44, 283-290.

Horowitz, M.,Wilner, N.,\&Alvarez,W. (1979). Impact of Event Scale: A measure of subjective stress. Psychosomatic Medicine, 41, 209-218.

Hoven, C.W., Duarte, C. S., Lucas, C. P.,Wu, P.,Mandell, D. J., Goodwin, R. D., et al. (2005).

Psychopathology among New York City public school children 6 months after September 11. Archives of General Psychiatry, 62, 545-551.

La Greca, A. M., Silverman, W. K., Vernberg, E. M., \& Prinstein, M. J. (1996).

Symptoms of posttraumatic stress in children after Hurricane Andrew: A prospective study. Journal of Consulting and Clinical Psychology, 64, 712- 723.

Lonigan, C. J., Shannon, M. P., Taylor, C. M., Finch, A. J. Jr, \& Sallee, F. R.

(1989). Children exposed to disaster: II. Risk factors for the development of post-traumatic symptomatology. Journal of the American Academy of Child and Adolescent Psychiatry, 33, 94-105.

Meesters, C., Muris, P., Ghys, A., Reumerman, T., \& Rooijmans, M. (2003).

The Children's Somatization Inventory: Further evidence for its reliability and validity in a pediatric and a community sample of Dutch children and adolescents. Journal of Pediatric Psychology, 28, 413-422.

Meier, P.,Mellenbergh, G. J., \& deWit, C. A.M. (1986). De Korte Depressie Vragenlijst voor Kinderen, KDVK [The Short Depression Inventory for Children, SDIC]. Nederlands tijdschrift voor de psychologie, 41, 364368.

Meiser-Stedman, R., Smith, P., Glucksman, E., Yule, W., \& Dalgleish, T. (2007).

Parent and child agreement for acute stress disorder, post-traumatic stress disorder and other psychopathology in a prospective study of children and adolescents exposed to single-event trauma. Journal of Abnormal Child Psychology, 35, 191-201.

Muris, P.,Merckelbach, H., Schmidt, H., \&Mayer, B. (1999). The revised version of the Screen for Child Anxiety Related Emotional Disorders (SCARED-R): Factor structure in normal children. Personality and Individual Differences, 26, 99-112. 
Boer, F., Smit, C., Morren, M., Roorda, J., Yzermans, J. Impact of a technological disaster on young children: a five-year postdisaster multiinformant study. Journal of Traumatic Stress: 2009, 22(6), 516-524

Muris, P., Merckelbach, H., Ollendick, T., King, N., \& Bogie, N. (2002). Three traditional and three new newiver childhood anxiety questionnaires: Their reliability and validity in a normal adolescent sample. Behavioural Research and Therapy, 40, 753-772.

Muris, P., Dreessen, L., B“ogels, S., Weckx, M., \& van Melick, M. (2004). A questionnaire for screening a broad range of DSM-defined anxiety disorder symptoms in clinically referred children and adolescents. Journal of Child Psychology and Psychiatry, 45, 813-820.

Neuner, F., Schauer, E., Catani, C., Ruf, M., \& Elbert, T. (2006). Post-tsunami stress: A study of posttraumatic stress disorder in children living in three severely affected regions in Sri Lanka. Journal of Traumatic Stress, 19, 339-347.

Olff, M. (2005). CRIES-13 voor kinderen en ouders van jonge kinderen [CRIES- 13 for children and parents of young children]. Amsterdam: Amsterdam Medical Centre.

Pfefferbaum, B., Nixon, S. J., Tucker, P. M., Tivis, R. D., Moore, V. L., Gurwitch, R. H., et al. (1999). Posttraumatic stress responses in bereaved children after the Oklahoma City bombing. Journal of the American Academy of Child and Adolescent Psychiatry, 38, 1372-1379.

Proctor, L. J., Fauchier, A., Oliver, P. H., Ramos, M. C., \& Margolin, G. (2007).

Family context and young children's responses to earthquake. Journal of Child Psychology and Psychiatry, 48, 941-949.

Roorda, J., van Stiphout,W. A., \& Huijsman-Rubingh, R. R. (2004). Post-disaster health effects: Strategies for investigation and data collection. Experiences from the Enschede firework disaster. Journal of Epidemiology and Community Health, 58, 982-987.

Sandberg, S., McGuinness, D., Hillary, C., \& Rutter, M. (1998). Independence of childhood life events and chronic adversities: A comparison of two patient groups and controls. Journal of the American Academy of Child and Adolescent Psychiatry, 37, 728-735.

Shemesh, E., Newcorn, J. H., Rockmore, L., Shneider, B. L., Emre, S., Gelb, B. D., et al. (2005). Comparison of parent and child report of emotional trauma symptoms in pediatric outpatient settings. Pediatrics, 115, 582-589.

Smilde-van den Doel, D., Smit, C., \&Wolleswinkel-van den Bosch, J. H. (2006).

School performance and social-emotional behavior of primary school children before and after a disaster. Pediatrics, 118, e1311-e1320.

Smith, P., Perrin, S., Dyregrov, A., \& Yule, W. E. (2003). Principal components analysis of the Impact of Event Scale with children in war. Personality and Individual Differences, 34, 315-322.

van Widenfelt, B. M., Goedhart, A. W., Treffers, P. D., \& Goodman, R.

(2003). Dutch version of the Strengths and Difficulties Questionnaire (SDQ).

European Child and Adolescent Psychiatry, 12, 281-289.

Vila, G., Witkowski, P., Tondini, M. C., Perez-Diaz, F., Mouren-Simeoni, M. C., \& Jouvent, R. (2001). A study of posttraumatic disorders in children who experienced an industrial disaster in the Briey region. European Child and Adolescent Psychiatry, 10, 10-18.

Walker, L. S., \& Garber, J. (1992), Children's Somatization Inventory: Preliminary manual. Nashville, TN: Vanderbilt University Medical Center.

Weems, C. F., Watts, S. E., Marsee, M. A., Taylor, L. K., Costa, N. M., Cannon, M. F., et al. (2007). The psychosocial impact of Hurricane Katrina: Contextual differences in psychological symptoms, social support, and discrimination.

Behavioural Research and Therapy, 45, 2295-2306. 
Boer, F., Smit, C., Morren, M., Roorda, J., Yzermans, J. Impact of a technological disaster on young children: a five-year postdisaster multiinformant study. Journal of Traumatic Stress: 2009, 22(6), 516-524

\section{TABLES}

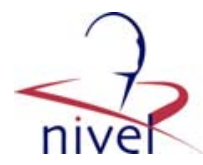

Table 1. Prevalence of Child- and Parent-Reported Health Problems

\begin{tabular}{|c|c|c|c|c|c|c|}
\hline & \multirow{2}{*}{\multicolumn{2}{|c|}{$\begin{array}{c}\text { Study group } \\
N=779\end{array}$}} & \multirow{2}{*}{\multicolumn{2}{|c|}{$\begin{array}{l}\text { Control } \\
N=515\end{array}$}} & \multicolumn{2}{|c|}{ Exposed vs. controls } \\
\hline & & & & & \multirow[b]{2}{*}{$\mathrm{OR}^{a}$} & \multirow[b]{2}{*}{$95 \% \mathrm{CI}$} \\
\hline & $n$ & $\%$ & $\%$ & $\%$ & & \\
\hline \multicolumn{7}{|l|}{ Child-report } \\
\hline \multicolumn{7}{|l|}{ Mental health problems (SDQ) } \\
\hline Conduct problems & 95 & 12.3 & 15.8 & 10.5 & $1.62^{*}$ & $1.02-2.56$ \\
\hline Emotional problems & 168 & 21.7 & 24.2 & 20.5 & 1.24 & $0.86-1.78$ \\
\hline Hyperactivity/inattention & 130 & 16.8 & 22.7 & 13.8 & $1.71^{*}$ & $1.15-2.54$ \\
\hline Peer problems & 123 & 15.9 & 15.8 & 16.0 & 0.97 & $0.64-1.47$ \\
\hline Prosocial behavior & 71 & 9.2 & 11.5 & 8.0 & 1.58 & $0.95-2.64$ \\
\hline Total score & 150 & 19.4 & 23.8 & 17.2 & 1.44 & $0.99-2.11$ \\
\hline \multicolumn{7}{|l|}{ Anxiety (SCARED) } \\
\hline Panic disorder symptoms & 20 & 2.6 & 2.7 & 2.5 & 1.10 & $0.43-2.83$ \\
\hline Social phobia symptoms & 88 & 11.5 & 13.3 & 10.6 & 1.28 & $0.8-2.04$ \\
\hline $\begin{array}{l}\text { Generalized anxiety } \\
\text { disorder symptoms }\end{array}$ & 33 & 4.3 & 6.2 & 3.3 & 1.63 & $0.78-3.39$ \\
\hline $\begin{array}{l}\text { Separation anxiety } \\
\text { disorder symptoms }\end{array}$ & 11 & 1.4 & 1.9 & 1.2 & 1.38 & $0.36-5.22$ \\
\hline Depressed feelings (SDIC) & 38 & 4.9 & 6.2 & 4.3 & 1.44 & $0.73-2.81$ \\
\hline $\begin{array}{l}\text { Posttraumatic symptoms } \\
\text { (CRIES-13) }\end{array}$ & 194 & 25.4 & 30.5 & 23.4 & 1.39 & $0.98-1.96$ \\
\hline Physical symptoms (CSI) & 211 & 27.3 & 32.0 & 25.0 & $1.42^{*}$ & $1.02-1.99$ \\
\hline \multicolumn{7}{|l|}{ Parent-report } \\
\hline \multicolumn{7}{|l|}{ Mental health problems (SDQ) } \\
\hline Conduct problems & 82 & 10.5 & 15.2 & 8.2 & $2.00^{*}$ & $1.23-3.24$ \\
\hline Emotional problems & 137 & 17.6 & 25.0 & 13.8 & $1.99^{*}$ & $1.35-2.94$ \\
\hline Hyperactivity/inattention & 109 & 14.0 & 19.3 & 11.3 & $1.80^{*}$ & $1.17-2.77$ \\
\hline Peer problems & 126 & 16.2 & 20.1 & 14.2 & 1.49 & $0.99-2.23$ \\
\hline Prosocial behavior & 29 & 3.7 & 4.2 & 3.5 & 0.94 & $0.41-2.15$ \\
\hline Total score & 90 & 11.6 & 19.3 & 7.6 & $2.95^{*}$ & $1.83-4.74$ \\
\hline \multicolumn{7}{|l|}{ Anxiety (SCARED) } \\
\hline Panic disorder symptoms & 4 & 0.5 & 1.1 & 0.2 & 7.06 & $0.62-80.19$ \\
\hline Social phobia symptoms & 38 & 4.9 & 6.5 & 4.1 & 1.58 & $0.81-3.07$ \\
\hline $\begin{array}{l}\text { Generalized anxiety } \\
\text { disorder symptoms }\end{array}$ & 18 & 2.3 & 3.8 & 1.6 & 2.62 & $0.98-7.00$ \\
\hline $\begin{array}{l}\text { Separation anxiety } \\
\text { disorder symptoms }\end{array}$ & 7 & 0.9 & 1.9 & 0.4 & 4.92 & $0.89-27.29$ \\
\hline Depressed feelings (SDIC) & 17 & 2.2 & 3.1 & 1.8 & 1.90 & $0.69-5.19$ \\
\hline $\begin{array}{l}\text { Posttraumatic symptoms } \\
\text { (CRIES-13) }\end{array}$ & 65 & 8.5 & 12.6 & 6.8 & $1.68^{*}$ & $1.00-2.85$ \\
\hline Physical symptoms (CSI) & 76 & 9.8 & 13.4 & 8.0 & $1.73^{*}$ & $1.06-2.82$ \\
\hline
\end{tabular}

Note. $\mathrm{SDQ}=$ Strengths and Difficulties Questionnaire; SCARED = Screen for Child Anxiety Related Emotional Disorders; SDIC = Short Depression Inventory for Children; CRIES = Children's Impact of Events Scales CSI = Children's Somatisation Inventory.

${ }^{2}$ ORs are adjusted for child gender, household marital status, education of mother, ethnicity, socioeconomic status, one or more traumatic experiences.

${ }^{*} p<.05$. 
Boer, F., Smit, C., Morren, M., Roorda, J., Yzermans, J. Impact of a technological disaster on young children: a five-year postdisaster multiinformant study. Journal of Traumatic Stress: 2009, 22(6), 516-524

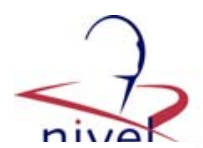

Table 2. Comparison of Child- and Parent-Reported Differences in the Health of Children Exposed by the Disaster and Controls: Multilevel Analysis ${ }^{2}$

\begin{tabular}{|c|c|c|c|c|c|c|}
\hline & \multicolumn{2}{|c|}{ Exposed } & \multicolumn{2}{|c|}{ Source Child vs. parent } & \multicolumn{2}{|c|}{ Interaction of Exposed $\times$ Source } \\
\hline & OR & $95 \%$ CI & OR & $95 \% \mathrm{CI}$ & OR & $95 \% \mathrm{CI}$ \\
\hline \multicolumn{7}{|l|}{ Mental health problems (SDQ) } \\
\hline Conduct problems & $2.06^{*}$ & $1.27-3.32$ & 1.35 & $0.87-2.08$ & 0.75 & $0.39-1.46$ \\
\hline Emotional problems & $2.04^{*}$ & $1.39-3.00$ & $1.64^{*}$ & $1.17-2.29$ & $0.58^{*}$ & $0.34-0.99$ \\
\hline Hyperactivity/inattention & $1.83^{*}$ & $1.20-2.79$ & 1.30 & $0.89-1.89$ & 0.91 & $0.51-1.61$ \\
\hline Peer problems & $1.50^{*}$ & $1.00-2.24$ & 1.18 & $0.83-1.68$ & 0.64 & $0.36-1.14$ \\
\hline Prosocial behavior & 0.98 & $0.43-2.22$ & $2.35^{*}$ & $1.33-4.17$ & 1.60 & $0.61-4.17$ \\
\hline Total score & $2.98^{*}$ & $1.88-4.72$ & $2.70^{*}$ & $1.80-4.07$ & $0.47^{*}$ & $0.26-0.85$ \\
\hline \multicolumn{7}{|l|}{ Anxiety (SCARED) } \\
\hline Panic disorder symptoms & 6.04 & $0.63-58.31$ & $13.52^{*}$ & $1.77-103.18$ & 0.18 & $0.02-2.09$ \\
\hline Social phobia symptoms & 1.58 & $0.82-3.06$ & $2.75^{*}$ & $1.63-4.62$ & 0.80 & $0.36-1.80$ \\
\hline $\begin{array}{l}\text { Generalized anxiety disorder } \\
\text { symptoms }\end{array}$ & 2.48 & $0.96-6.43$ & 2.19 & $0.93-5.15$ & 0.67 & $0.20-2.21$ \\
\hline $\begin{array}{l}\text { Separation anxiety disorder } \\
\text { symptoms }\end{array}$ & $5.53^{*}$ & $1.04-29.37$ & 3.07 & $0.61-15.43$ & 0.26 & $0.03-2.14$ \\
\hline Depressed feelings (SDIC) & 1.77 & $0.67-4.67$ & $2.54^{*}$ & $1.15-5.61$ & 0.82 & $0.25-2.67$ \\
\hline Posttraumatic symptoms (CRIES-13) & $1.78^{*}$ & $1.06-2.99$ & $4.08^{*}$ & $2.72-6.13$ & 0.76 & $0.41-1.42$ \\
\hline Physical symptoms (CSI) & $1.78^{*}$ & $1.10-2.88$ & $3.83^{*}$ & $2.62-5.59$ & 0.79 & $0.44-1.41$ \\
\hline
\end{tabular}

Note. SDQ = Strengths and Difficulties Questionnaire; SCARED = Screen for Child Anxiety Related Emotional Disorders, SDIC = Short Depression Inventory for Children; CRIES = Children's Impact of Events Scale; CSI = Children's Somatisation Inventory.

${ }^{2}$ ORs are adjusted for gender of child, marital status in household, education of mother, ethnicity, socioeconomic status, and one or more traumatic experiences in all three columns. In Column 1 Exposed ORs are also adjusted for source child report or parent report, and effect modification of source with exposed. In Column 2 Source, ORs are also adjusted for exposure exposed or control, and effect modification of exposure with source. In column 3 Interaction ORs are also adjusted for exposure exposed or control, and source child report or parent report. The reference category of the OR in column 1 is nonexposed children and nonexposed parents, in column 2 parents of nonexposed children, and in column 3 all parents and nonexposed children.

${ }^{*} p<.05$.

\section{FIGURES}

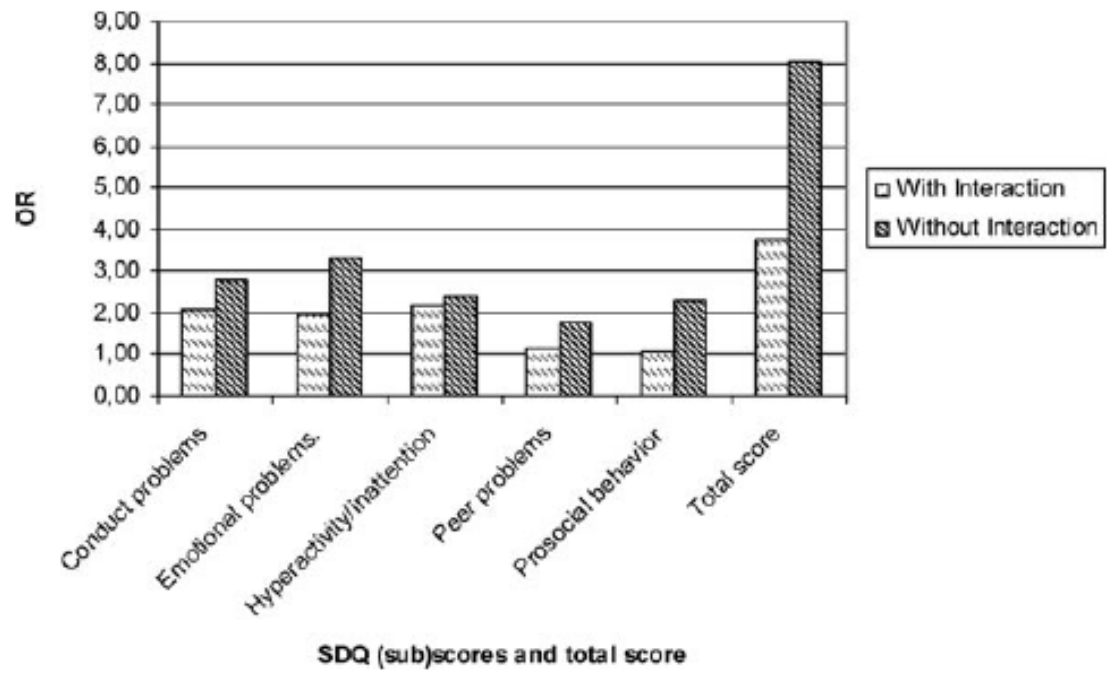

Figure 1. Odds ratios of mental health problems with and without interaction between exposure and source. SDQ $=$ Strengths and Difficulties Questionnaire. 